\title{
Passive secretory immunity against Salmonella typhimurium demonstrated with foster mouse pups
}

\author{
S. R. SHOPE and D. A. SCHIEMANN* \\ Department of Microbiology, Montana State University, Bozeman, MT 59717, USA
}

\begin{abstract}
Summary. Mice immunised by drinking water containing an $\mathrm{Aro}^{-}$mutant strain of Salmonella typhimurium produced intestinal $\mathrm{IgA}$ antibodies after a memory response which was demonstrated by measuring copro-antibodies. After oral challenge with a virulent strain of $S$. typhimurium, foster mouse pups placed with immunised mothers survived longer than control pups held with non-immunised mothers.
\end{abstract}

\section{Introduction}

The young of mammals may receive passive maternal antibody prenatally through cross-placental transmission, limited to IgG immunoglobulins, or through yolk-sac absorption; they may also receive it postnatally through colostrum and mother's milk. ${ }^{1}$ Ungulates such as cows and pigs receive nearly all of their maternal antibody through colostrum, whereas primates, rabbits and guinea-pigs receive most of their maternal antibody by placental transmission. Rodents and dogs are intermediate, receiving some maternal antibody prenatally but acquiring more postnatally. The ability to absorb from the gut antibody, which appears to be limited to IgG immunoglobulins, and the half-life of passive serum antibody, also vary among young mammals. Gut absorption of antibody stops within $24 \mathrm{~h}$ in calves but extends to 14-20 days in rats and mice. Passive immunity in rats and mice due to maternal antibody, declining rapidly about 10 days after birth, has been demonstrated against a variety of micro-organisms. ${ }^{1,2}$

It has become increasingly apparent that the secretory immune system plays an important role in host defence against enteropathogenic bacteria, and that vaccination against pathogenic bacteria that colonise or invade through the mucosa is likely to be more effective by oral rather than parenteral routes. ${ }^{3,4}$ Salmonellosis and typhoid fever are diseases contracted primarily through the gastrointestinal tract. Several types of avirulent mutant strains of Salmonella typhimurium have been generated in recent years for studying their potential as vaccines in a mouse model of typhoid fever. Because $\mathrm{Aro}^{-}$mutant strains such as those developed by Hoiseth and Stocker, ${ }^{5}$ have a requirement for aromatic compounds not found in

Received 23 Sep. 1990; accepted 20 Nov. 1990.

* Correspondence should be sent to Dr D. A. Schiemann. mammalian tissue, their capacity for survival in vivo is reduced. Mutant strains of this kind have been evaluated as vaccines in several studies. ${ }^{6-8}$

We describe in this paper the arousal of an intestinal IgA memory response in mice after oral immunisation with an $\mathrm{Aro}^{-}$mutant strain of $S$. typhimurium, and passive immune protection against oral challenge with $S$. typhimurium in foster pups placed with immunised mothers.

\section{Materials and methods}

\section{Bacteria}

Two experimental strains of S. typhimurium were used in this study. Strain SL3201, a representative of the FIRN biotype, carries a plasmid (60 Mda) associated with virulence, and this strain is highly virulent for BALB/c mice. Strain SL3235, an Aro mutant strain derived from strain SL3201, also carries this 60Mda plasmid associated with mouse virulence (fig. 1) and was received from Professor B.A.D. Stocker, Stanford University, CA, USA.

Experimental strains of bacteria were maintained in peptone $1 \% \mathrm{w} / \mathrm{v}$ containing glycerol $40 \% \mathrm{v} / \mathrm{v}$ at $-20^{\circ} \mathrm{C}$ and subcultured twice in brain heart infusion broth before use. The densities of bacterial suspensions were determined by colony counts on trypticase soy agar containing yeast extract $0.6 \% \mathrm{w} / \mathrm{v}$.

Plasmids extracted from bacterial cultures by the method of Marko et al. ${ }^{9}$ were identified by agar-gel electrophoresis. Reference plasmids were: one of 60 Mda from S. typhimurium strain X3306 obtained from Professor R. Curtiss, Washington University, MO, USA; one of $86 \mathrm{Mda}$ from a strain of Escherichia coli obtained from Dr Diane Taylor, University of Alberta, Canada; and those of 26, 46 and $72 \mathrm{Mda}$ from strains of E. coli obtained from the National Collection of Type Cultures, London. 


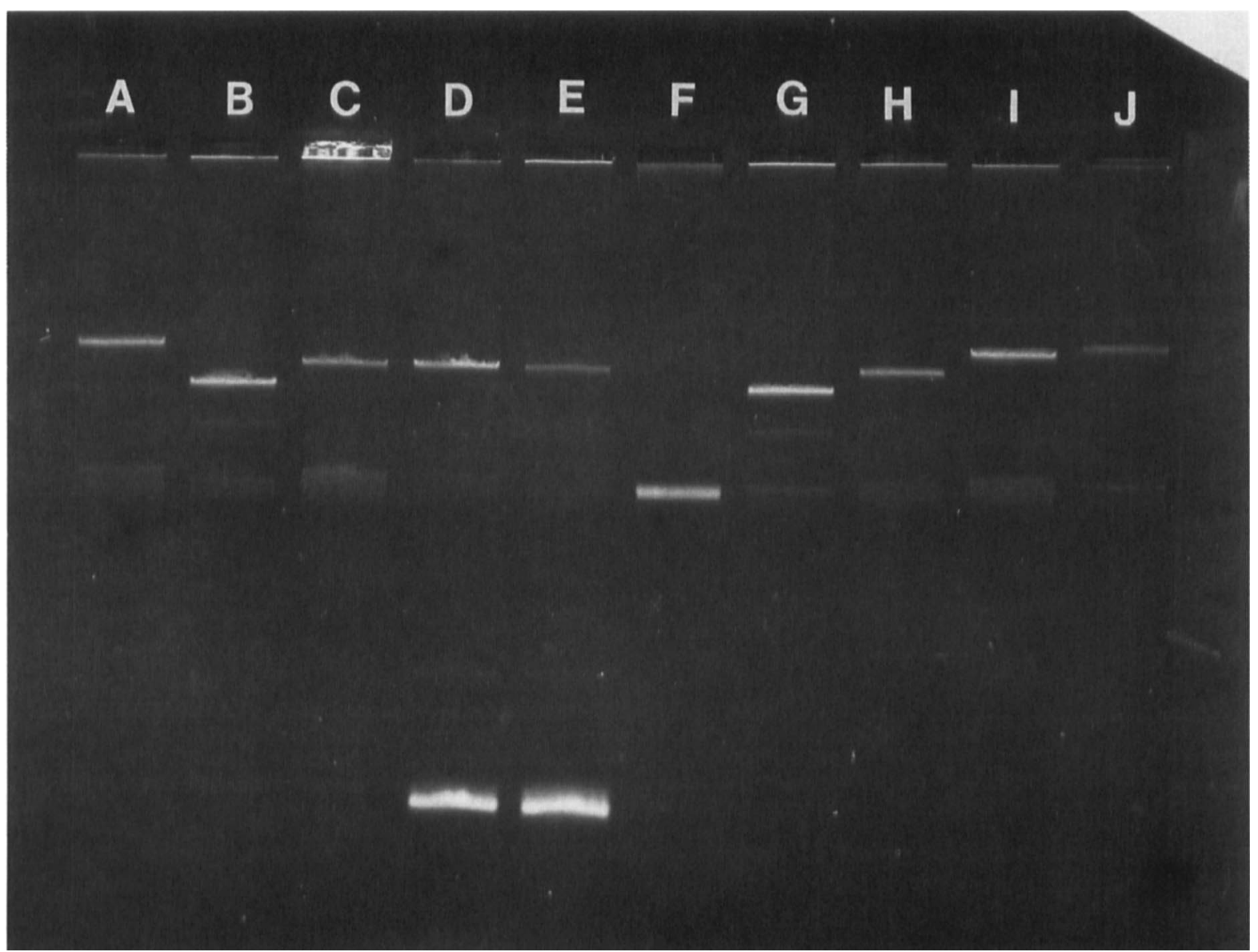

Fig. 1. Agarose-gel electrophoresis showing plasmids of S. typhimurium strains SL3235 and SL3201 (lanes D and E), and mol.-wt reference plasmids of 86 Mda (lanes A and J), 72 Mda (lane I), 60 Mda (lanes C and H), 46 Mda (lanes B and G) and 26 Mda (lane F).

\section{In-vitro interactions between bacteria and epithelial cells}

The adhesion and invasion properties of experimental strains of S. typhimurium were determined with Henle 407 intestinal epithelial cells in tissue cultures by a method described previously, ${ }^{10}$ modified by the inclusion of fixed cells for determining the activity of gentamicin in situ. This procedure provides six bacterial counts identified in table I as: (i) "Added," the number of bacteria introduced to each cell monolayer, allowing expression of associated bacteria as a percentage of the inoculum; (ii) "Associated," the total number of bacteria that remain associated after interaction and washing of each cell monolayer, representing extracellular attached and intracellular bacteria; (iii) "Intracellular," the number of bacteria surviving gentamicin treatment for each cell monolayer, representing intracellular bacteria; (iv) "Plastic," the total number of bacteria associated with wells that did not receive Henle 407 cells but were otherwise treated similarly, providing a basis for judging the relative affinity of bacteria for cells compared to that for polystyrene; (v) "Fixed-Associated," the total number of bacteria associated with each cell monolayer that was fixed with paraformaldehyde, representing extracellular attached bacteria only and (vi) "Fixed-Gentamicin," the number of bacteria on each fixed monolayer that survived gentamicin treatment. The latter two counts are used to support the interpretation that the count of survivors of gentamicin treatment with unfixed cells does in fact represent intracellular bacteria.

\section{Immunisation protocol}

Three oral immunisations with S. typhimurium strain SL3235 were provided by replacing the drinking water with a suspension of bacteria $\left(c .10^{8} / \mathrm{ml}\right.$ in peptone water $0.1 \% \mathrm{w} / \mathrm{v})$ and given to the mice for $24 \mathrm{~h}$. The first two oral immunisations were 1 week apart, after which immunised female mice were held with male mice for 5-7 days. The third immunisation was administered 19 days after the second, and about 1 week before parturition.

\section{Measurement of copro-antibodies}

Faeces were collected periodically from mice by placing them under a beaker on a wire screen lying on the base of a petri dish. The weight of collected faeces was calculated from the gross and tare weights of the petri dish. Faecal material was suspended in $3 \mathrm{ml}$ of buffer ( $50 \mathrm{~mm}$ edetic acid; trypsin inhibitor, $0.1 \mathrm{mg} /$ $\mathrm{ml} ; \mathrm{pH} \mathrm{7.2)}$ and broken up with a glass rod and 
vigorous vortex mixing. The volume was made up to $6 \mathrm{ml}$ with phosphate-buffered saline (PBS) and the suspension was centrifuged $\left(850 \mathrm{~g}\right.$ at $25^{\circ} \mathrm{C}$ for $\left.10 \mathrm{~min}\right)$. A 4-ml volume of supernate was transferred to a 50$\mathrm{ml}$ conical centrifuge tube and $100 \mu \mathrm{l}$ of phenylmethylsulphonyl fluoride (PMSF) was added (100 mM in ethanol $95 \%$ ). The suspension was centrifuged (22 $000 \mathrm{~g}$ at $4^{\circ} \mathrm{C}$ for $20 \mathrm{~min}$ ) and $3 \mathrm{ml}$ of supernate was removed for storage at $-20^{\circ} \mathrm{C}$ after addition of PMSF $(30 \mu \mathrm{l})$, sodium azide $1.0 \% \mathrm{w} / \mathrm{v}(30 \mu \mathrm{l})$ and fetal bovine serum $(150 \mu l)$.

Copro-antibodies were measured by an enzyme immunoassay (ELISA) with whole bacteria of S. typhimurium strain SL3201 as antigen, suspended at a dry wt of $20 \mu \mathrm{g} / \mathrm{ml}$ in carbonate coating-buffer $\left(0.04 \mathrm{M} \mathrm{Na}_{2} \mathrm{CO}_{3}, 0.06 \mathrm{M} \mathrm{NaHCO}_{3}, \mathrm{NaN}_{3}, 0.02 \% \mathrm{w} / \mathrm{v}\right.$, $\mathrm{pH} 9 \cdot 6)$ and added $(100 \mu \mathrm{l})$ to wells of a 96-well immunoassay plate (Nunc Immuno plate). Plates were held at $4^{\circ} \mathrm{C}$ overnight, wells were washed three times with PBS (each wash throughout the procedure included $5 \mathrm{~min}$ on a rocker), and treated with a blocking buffer (chicken egg albumin $2 \% \mathrm{w} / \mathrm{v}$ in PBS) for $3 \mathrm{~h}$ at room temperature. Blocking buffer was removed and plates were stored dry at $-20^{\circ} \mathrm{C}$.

Wells of antigen plates were washed three times with PBS before use. The sample (serum, or faeces adjusted so that $100 \mu$ l of extract represented $3 \mathrm{mg}$ wet weight of faeces), diluted when necessary in buffer (bovine serum albumin $0.1 \% \mathrm{w} / \mathrm{v}, \mathrm{BSA}$, in PBS), was added and the plate held overnight at $4^{\circ} \mathrm{C}$. Wells were washed five times with PBST (PBS containing Tween $200.05 \% \mathrm{v} / \mathrm{v}$ ), and treated with blocking buffer (BSA $1 \% \mathrm{w} / \mathrm{v}$ in PBS) for $1 \mathrm{~h}$. Wells were washed twice with PBST and goat anti-mouse immunoglobulin (IgA, IgM or IgG) (Kirkegaard and Perry) $(100 \mu \mathrm{l})$ was added at the following dilutions made in buffer (BSA $0.1 \% \mathrm{w} / \mathrm{v}$ in PBST): anti-mouse IgA, 1 in 4000; anti-mouse IgM, 1 in 2000; anti-mouse IgG 1 in 2000. The plate was held at room temperature for $2 \mathrm{~h}$ and wells were then washed five times with PBST. Antigoat IgG-alkaline phosphatase conjugate (Cappel) $(100 \mu \mathrm{l})$ was added at a dilution which varied with the isotype being measured: $\operatorname{IgA}, 1$ in $6000 ; \operatorname{IgM}, 1$ in $4000 ; \mathrm{IgG}, 1$ in 4000 . The plate was held at room temperature for $90 \mathrm{~min}$, washed five times with PBST, and enzyme substrate $\left[\mathrm{Na}_{2} p\right.$-nitrophenyl phosphate, $1 \mathrm{mg} / \mathrm{ml}$ in diethanolamine buffer (diethanolamine, $9.7 \% \mathrm{v} / \mathrm{v} ; 50 \mathrm{mM} \mathrm{MgCl} 2 ; \mathrm{pH} 9.8)](200 \mu \mathrm{l})$ was added. The plate was sealed and incubated at $37^{\circ} \mathrm{C}$ by floating in a waterbath for $2 \mathrm{~h}$. The enzyme reaction was stopped by adding $3 \mathrm{~N} \mathrm{NaOH}(100 \mu \mathrm{l})$ to each well, and the concentration of chromogen was measured by determining the absorbance at $405 \mathrm{~nm}$ with an automated ELISA reader (BioRad).

Each ELISA plate included a negative control consisting of either normal mouse serum or an extract of pooled faeces collected from non-immunised mice, and a positive control consisting of serum from immunised mice or an extract of faeces containing natural $\operatorname{IgA}$ against $S$. typhimurium aroused by oral immunisation, IgG by supplementing with serum from an immunised mouse, and IgM by supplementing with a monoclonal antibody prepared against $S$. typhimurium. The ELISA results for test samples were converted to positive/negative $(\mathrm{P} / \mathrm{N})$ ratios, i.e., the ratio of the $A_{405}$ for the test sample to that for the negative sample, as described by Briggs and Skeeles. ${ }^{11}$ A $\mathrm{P} / \mathrm{N}$ ratio of 1.0 represents a negative test result. Each assay included triplicate wells with the results converted to the arithmetic mean and standard deviation.

\section{Foster pups}

Natural mouse pups from immunised female mice were removed $24 \mathrm{~h}$ after birth and replaced by eight pups of the same age taken from non-immunised female mice. Two days later, foster pups and an equal number of control pups left with their natural nonimmunised mothers were challenged by oral administration of $20 \mu \mathrm{l}$ of gelatin $0.1 \% \mathrm{w} / \mathrm{v}$ saline containing c. $10^{3}$ cfu of $S$. typhimurium strain SL3201. The pups in the test and control groups were checked at least once daily over 22 days to facilitate prompt removal of dead animals and to record the number of days between challenge and death.

\section{Results}

\section{In-vitro interactions with epithelial cells}

We found that anaerobic growth of strains of $S$. typhimurium increased their invasion of epithelial cells in tissue cultures. Therefore, the adhesion and invasion properties of the two experimental strains of S. typhimurium were compared with anaerobically grown cultures. The results (table I) indicated that adhesion and invasion with Henle 407 cells were

Table I. Interactions of anaerobically grown $S$. typhimurium with Henle 407 epithelial cells

\begin{tabular}{|c|c|c|}
\hline \multirow[t]{2}{*}{ Loaation of bacteria } & \multicolumn{2}{|c|}{$\begin{array}{c}\text { Mean }\left(\log _{10}\right) \text { number of bacteria } \\
\text { and standard deviation per } \\
\text { monolayer } \dagger\end{array}$} \\
\hline & Strain SL3201 & Strain SL3235 \\
\hline Added & 6.42 SD 5.24 & 6.79 SD $\quad 6.27$ \\
\hline $\begin{array}{l}\text { Associated (percentage of } \\
\text { added) } \\
\text { Intracellular (percentage of } \\
\text { associated) } \\
\text { Plastic (percentage of added) } \\
\text { Fixed-Associated (percentage } \\
\text { of added) } \\
\text { Fixed-Gentamicin (percent- } \\
\text { age kill) }\end{array}$ & $\begin{array}{c}6.05 \text { SD } 5 \cdot 38 \\
(42.5 \text { SD } 10.4) \\
5.93 \text { SD } 5 \cdot 37 \\
(75 \cdot 5 \text { SD } 18 \cdot 2) \\
5 \cdot 37 \text { SD } 5 \cdot 19 \\
(9.0 \text { SD } 6.2) \\
5 \cdot 70 \text { SD } 5 \cdot 56 \\
(19.4 \text { SD } 14.5) \\
2.54 \text { SD } 2 \cdot 41 \\
(99.91 \text { SD } 0.08)\end{array}$ & 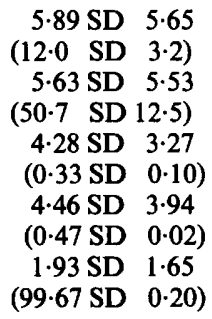 \\
\hline
\end{tabular}

* See Materials and methods.

$\dagger$ Arithmetic mean and SD for three experiments, each representing composite of three monolayers. 
essentially the same for the two experimental strains of S. typhimurium. However, for reasons unknown to us, the mutant strain SL3235 showed reduced association for plastic and fixed cells.

\section{Passive immunity in foster pups}

Control and foster pups, 24 of each and with each group derived from three litters, were placed with three non-immunised or immunised mothers, respectively. Six of the foster pups were removed from the experiment after 9 days because of the death of one mother. The survival time for $50 \%$ of the foster pups placed with immunised mothers was 12 days with three pups still alive after 22 days (fig. 2). In contrast, the survival time for $50 \%$ of the control pups was 8 days with none surviving beyond 9 days. This type of passive protection in foster mouse pups was demonstrated in other experiments; however, the data are not presented here because antibody responses were not measured.

\section{Intestinal antibody responses in immunised mice}

Immune responses to oral immunisation with S. typhimurium strain SL3235 were monitored with five sentinel mice in order to avoid the repeated handling of pregnant females as was required for the collection of faeces. These sentinel mice were immunised and otherwise handled in exactly the same manner as the female mice which had been bred and used for feeding of foster pups. Two baseline measurements were made before the first oral immunisation. There was little or no response for all three isotypes of copro-antibodies against $S$. typhimurium with the first two oral immunisations 1 week apart (figs. 3-7). However, the third oral immunisation, coming 19 days after the second, aroused a memory response that produced large increases in IgA antibody in all five mice. These sentinel mice were synchronised with the pregnant females so that the elevated levels of IgA antibody may be presumed to have been present in

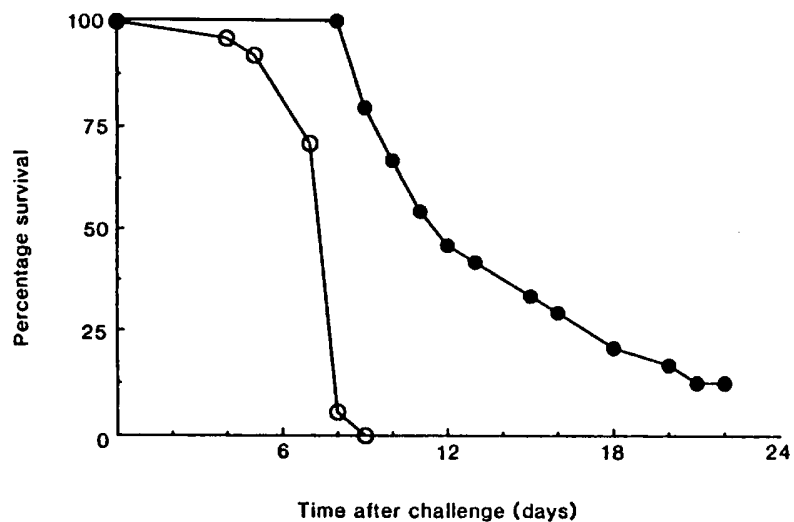

Fig. 2. Survival of foster mouse pups $(n=24)$ placed with three mothers immunised by drinking water containing $S$. typhimurium strain SL3235 $(O)$, and natural pups $(n=24)$ held with three nonimmunised mothers $(O)$, after oral challenge with $S$. typhimurium strain SL3201. Six foster pups were removed at 9 days because of the death of the mother. the mothers during at least the first 2 weeks of nursing the foster pups. Two sentinel mice also showed increases in faecal IgM antibody following the third booster, but none of the mice showed any increase in IgG antibody.

\section{Humoral antibody responses}

Blood was collected from the retrobulbar sinus of the sentinel mice before the first immunisation and at the end of the experiment. Sera were examined by determining isotype-specific ELISA titres against S. typhimurium strain SL3201. The results (table II) indicated modest increases in serum IgA and no greater than a four-fold increase in IgG in these sentinel mice. Four of the mice showed high preimmunisation titres of IgM antibody that dropped sharply. It is known that the rat and mouse fetus synthesise IgM antibody just before birth and that it begins to disappear about 3 weeks later. ${ }^{1}$ Pre-immune sera were collected when the mice were about 3 weeks old and this might explain our results; however, it

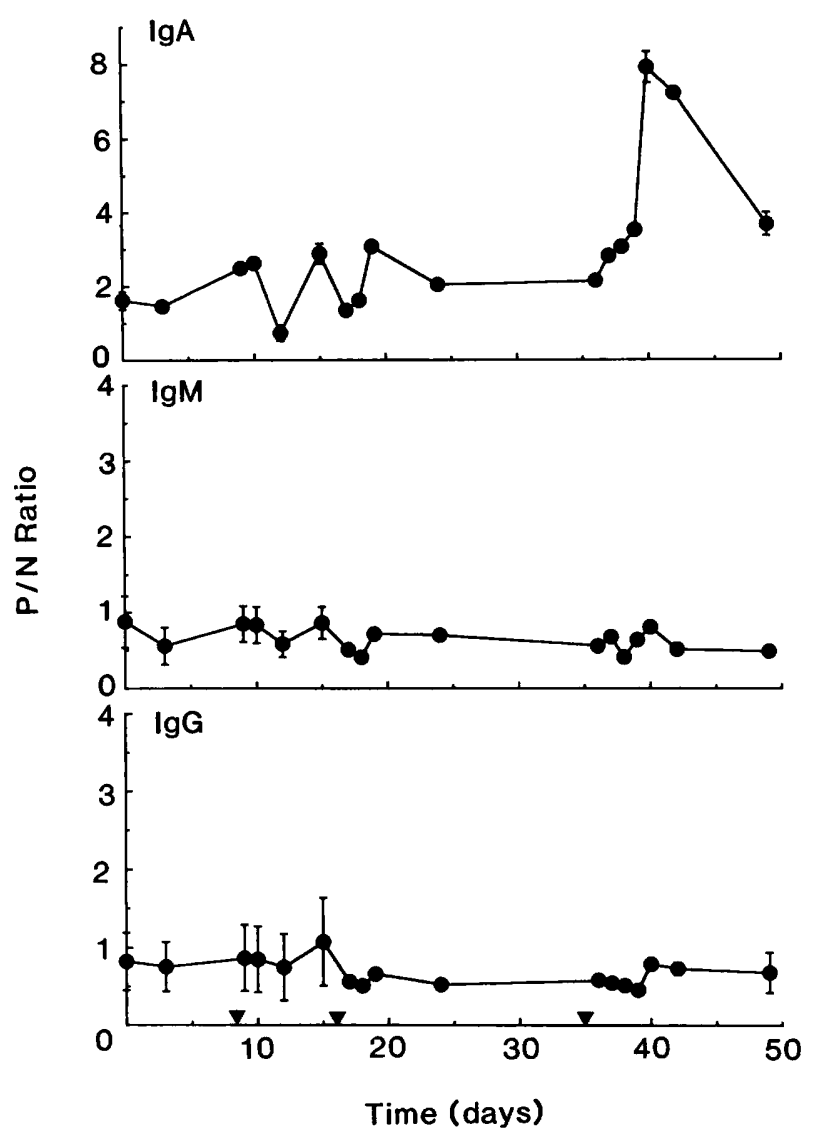

Fig. 3.

Figs. 3-7. Copro-antibodies against $S$. typhimurium measured by ELISA for sentinel mice, numbers 1-5 respectively, immunised three times $(\nabla)$ by drinking water with $S$. typhimurium strain SL3235. After the third immunisation, large increases in IgA antibody occurred with mice nos. 1, 4 and 5 (figs. 3,6 and 7); a large increase in $\operatorname{IgA}$ and $\operatorname{IgM}$ antibodies occurred with mouse no. 2 (fig. 4); and a large increase in IgA and a smaller increase in IgM antibodies occurred with muuse no. 4 (fig. 5 ). $\uparrow=$ result $>$ indicated value. 

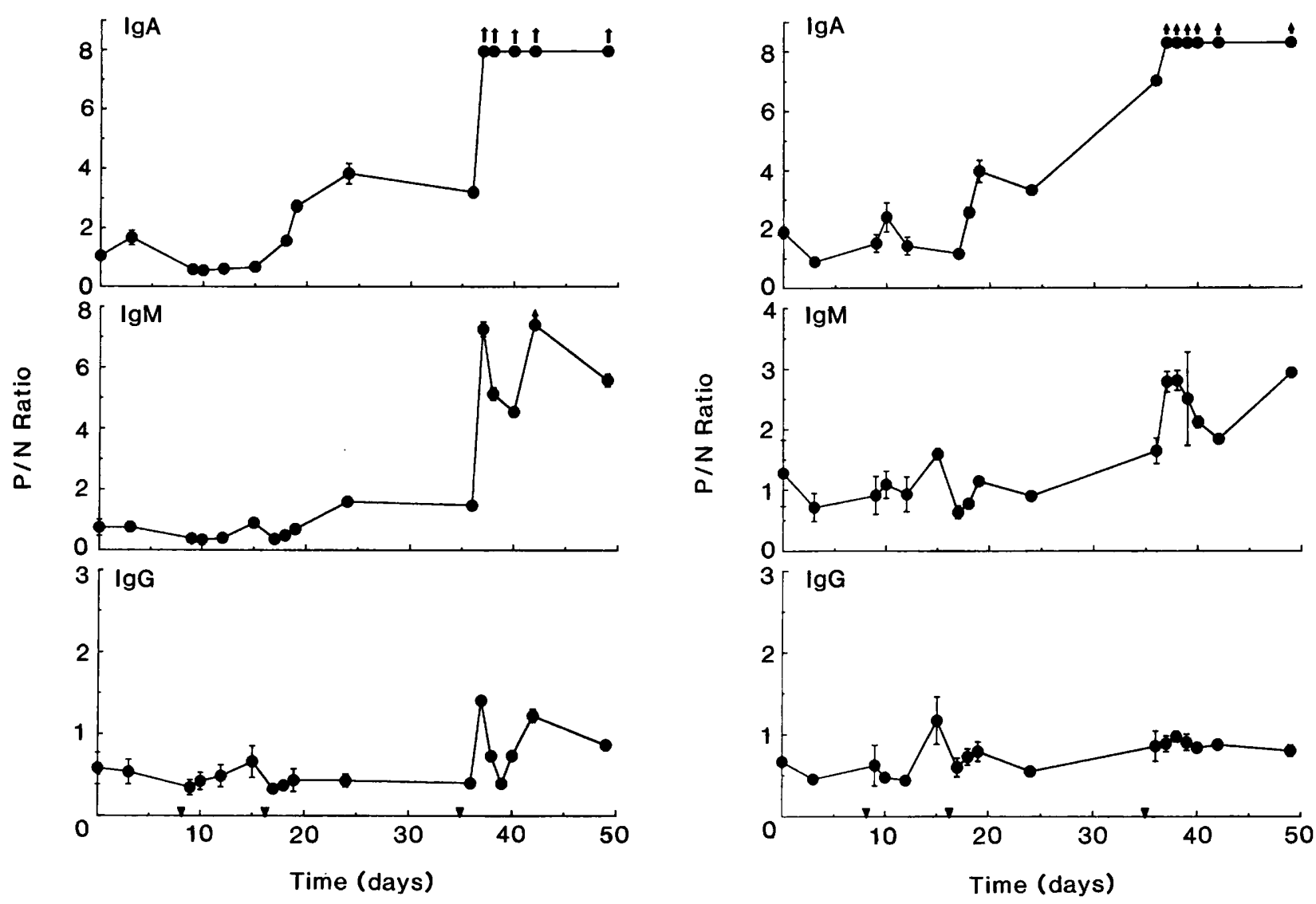

Fig. 4.

Fig. 5.

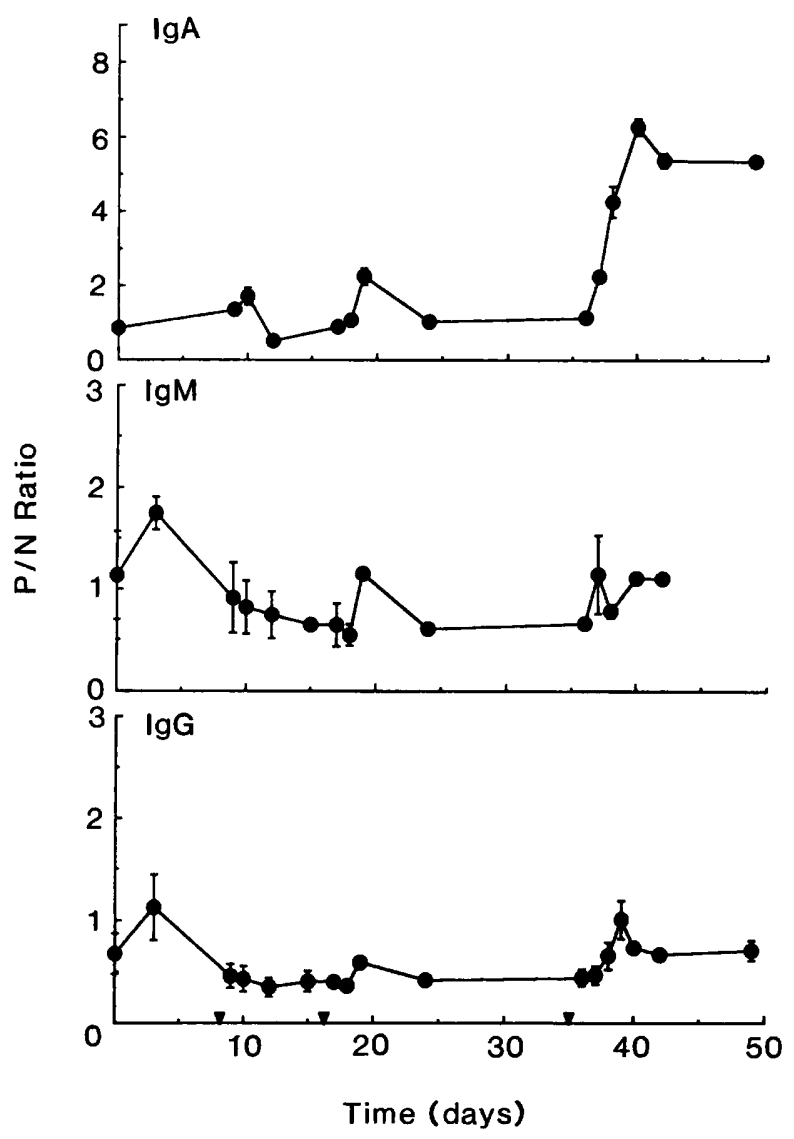

Fig. 6.

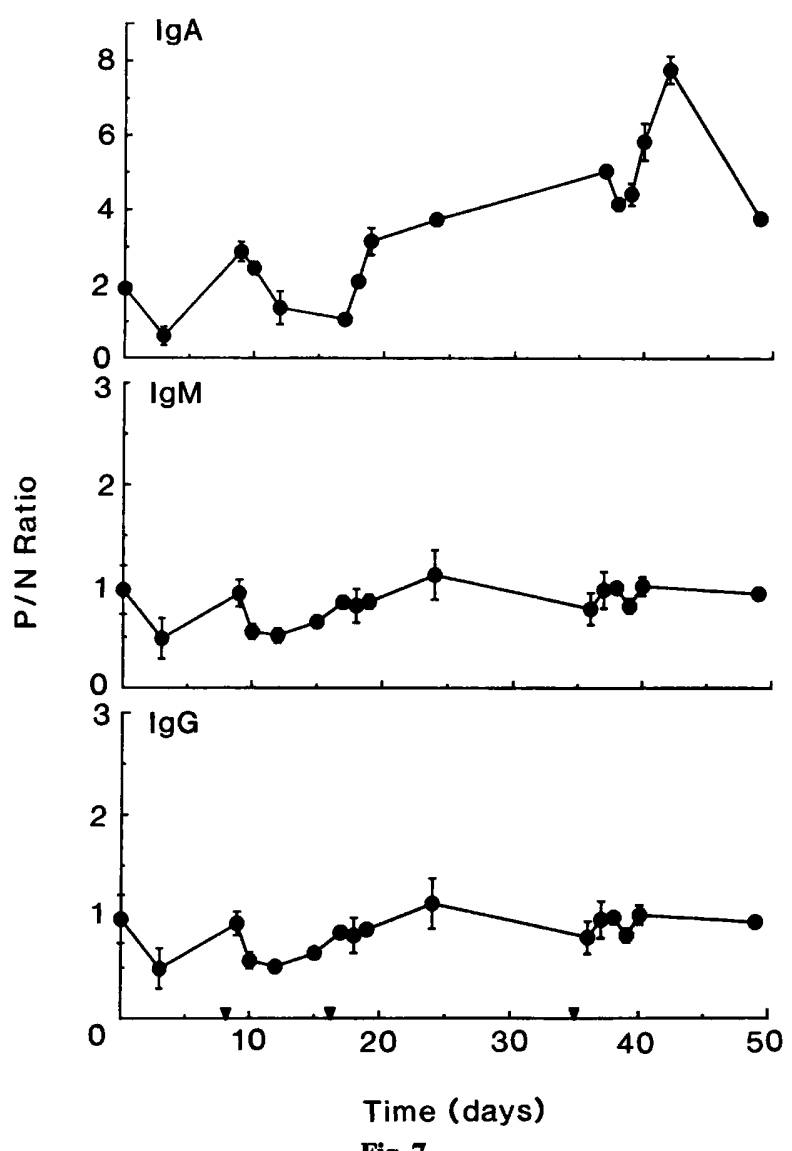

Fig. 7. 
Table II. Pre-immune and immune serum titres against $S$. typhimurium for five sentinel mice immunised three times by drinking water containing $S$. typhimurium strain SL 3235

\begin{tabular}{|c|c|c|c|c|c|c|}
\hline \multirow{3}{*}{$\begin{array}{c}\text { Mouse } \\
\text { no. }\end{array}$} & \multicolumn{6}{|c|}{ Serum titre* } \\
\hline & \multicolumn{3}{|c|}{ Pre-immune } & \multicolumn{3}{|c|}{ Immune } \\
\hline & IgA & IgM & IgG & IgA & IgM & IgG \\
\hline 1 & $<400$ & $>12800$ & 1600 & 3200 & 1600 & 3200 \\
\hline 2 & $<400$ & 12800 & 800 & 1600 & 1600 & 3200 \\
\hline 3 & $<400$ & 3200 & 400 & 400 & 1600 & 3200 \\
\hline 4 & $<400$ & 1600 & 400 & 400 & 3200 & 3200 \\
\hline 5 & $<400$ & 6400 & 400 & 400 & 1600 & 800 \\
\hline
\end{tabular}

* Highest dilution that gave mean $A_{405}(n=3)$ by ELISA that was greater than mean $A_{405}+2 S D$ for negative control $(n=3)$.

does not explain why the serum IgM antibody reacted with S. typhimurium.

\section{Discussion}

Adhesion and invasion of epithelial cells of an animal host are considered basic requisites of bacterial pathogenicity. ${ }^{12}$ The most apparent role of mucosal antibodies, especially $\operatorname{SIgA}$, is antigen exclusion. ${ }^{13}$ When these antibodies are directed against bacterial antigens that mediate adhesion or invasion, they may play an important role in preventing colonisation and infection of the host. ${ }^{14}$ It was considered important, therefore, to use a vaccine strain of $S$. typhimurium that retained the properties of adhesion and invasion and, presumably, all antigens mediating these processes. We confirmed this for the mutant strain used in this study by showing that its interactions with Henle 407 cells in tissue cultures were essentially the same as those of a highly virulent strain of $S$. typhimurium.

Our main interest in this study was to demonstrate the role of mucosal antibodies, particularly SIgA, in preventing colonisation by $S$. typhimurium. A fosterpup model was chosen because it eliminated any question of protection by antibody received from an immune mother through placental transmission. Culbertson ${ }^{15}$ concluded from his study with Trypanosoma lewisi that the immunity of normal nursing rat pups placed with an immune mother was as "secure and enduring" as that acquired by the young born of, and nursed by, an immune mother. Bruce-Chwatt and Gibson $^{16}$ demonstrated passive immunity against

\section{References}

1. Brambell FWR. The transmission of passive immunity from mother to young (Frontiers of biology, 18). Amsterdam, North-Holland Publishing Company. 1970.

2. Solomon JB. Foetal and neonatal immunology (Frontiers of biology, 20). Amsterdam, North-Holland Publishing Company. 1971 .

3. Hone D, Hackett J. Vaccination against enteric bacterial diseases. Rev Infect Dis 1989; 11 : 853-877.
Plasmodium berghei in baby rats, finding that litters from normal mothers placed with immune mothers showed greater protection than litters from immune mothers placed with normal mothers; this suggested that placental transmission of protection was not as important as that received through mother's milk.

Sentinel female mice were used to demonstrate that oral immunisation through drinking water resulted in the production of intestinal $\operatorname{IgA}$ and, accepting the existence of a common mucosal immune system, this antibody should also have been produced in the secretory tissue of the mammary gland. ${ }^{4}$ However, oral immunisation also results in a systemic immune response as was evident from increases in specific $\mathrm{IgG}$ antibody which, however, were relatively small $(\leq 8$ fold) in the serum of the immunised mice. The suckling foster mouse pups would also have received this antibody and absorbed it from the gut. Therefore, we have not completely resolved with this model the question of how much of the protection observed in foster pups was due to serum antibody acquired by gut absorption of milk antibody, and how much was due to intestinal IgA antibody which is confined to the gut.

The foster mouse-pup model suffered in one additional respect and that was the eventual death of many of the test animals with very few surviving the duration of the experiment. We believe this resulted from repeated exposure caused by infection of the mothers. Again, we believe that the mothers, although immunised, developed infections because of massive doses of bacteria received through ingestion of pup faeces, which they normally do in cleaning the young, and particularly through cannibalism. Mothers that died during the course of this and other experiments were found to have massive systemic infections, and even some that survived were found to be colonised with $S$. typhimurium. The mice were held on wire to reduce coprophagy, the cages were changed every second day, and pups were checked at least twice daily to remove dead animals, all of which did not prevent this problem. Nevertheless, the experimental results did demonstrate significant differences in survival times between foster pups placed with immunised mothers and pups held with their natural non-immunised mothers.

This work, contribution no. J2536 from the Montana Agricultural Experiment Station, was supported in part by a grant from the Southeastern Poultry and Egg Association.

4. McGhee JR, Mestecky J. In defense of mucosal surfaces: Development of novel vaccines for IgA responses protective at the portals of entry of microbial pathogens. Infect Dis Clin North Am 1990; 4: 315-341.

5. Hoiseth SK, Stocker BAD. Aromatic-dependent Salmonella typhimurium are non-virulent and effective as live vaccines. Nature 1981 ; 291 : 238-239.

6. Smith BP, Reina-Guerra M, Hoiseth SK et al. Aromaticdependent Salmonella typhimurium as modified live vaccines for calves. Am J Vet Res 1984; 45: 59-66. 
7. Killar LM, Eisenstein TK. Immunity to Salmonella typhimurium infection in $\mathrm{C} 3 \mathrm{H} / \mathrm{HeJ}$ and $\mathrm{C} 3 \mathrm{H} / \mathrm{HeNCrlBR}$ mice: studies with an aromatic-dependent live $S$. typhimurium strain as a vaccine. Infect Immun 1985; 47: 605-612.

8. Eisenstein TK, Dalal N, Killar L, Lee J-C, Schafer R. Paradoxes of immunity and immunosuppression in Salmonella infection. In: Eisenstein TK, Bullock WE, Hanna N (eds) Host defenses and immunomodulation to intracellular pathogens (Advances in experimental medicine and biology, 239). New York, Plenum Press. 1988: 353-366.

9. Marko MA, Chipperfield R, Birnboim HC. A procedure for the large-scale isolation of highly purified plasmid DNA using alkaline extraction and binding to glass powder. Anal Biochem 1982; 121 : 382-387.

10. Schiemann DA, Crane MR, Swanz PJ. Surface properties of Yersinia species and epithelial cell interactions in vitro by a method measuring total associated, attached and intracellular bacteria. J Med Microbiol 1987; 24: 205-218.

11. Briggs DJ, Skeeles JK. An enzyme-linked immunosorbent assay for detecting antibodies to Pasteurella multicoda in chickens. Avian Dis 1983; 28 : 208-215.

12. Arp LH. Bacterial infection of mucosal surfaces: an overview of cellular and molecular mechanisms. In: Roth JA (ed) Virulence mechanisms of bacterial pathogens. Washington, DC, American Society for Microbiology. 1988: 3-27.

13. Kilian M, Mestecky J, Russell MW. Defense mechanisms involving Fc-dependent functions of immunoglobulin A and their subversion by bacterial immunoglobulin $\mathbf{A}$ proteases. Microbiol Rev 1988; 52: 296-303.

14. Sherman DM, Acres SD, Sadowski PL et al. Protection of calves against fatal enteric colibacillosis by orally administered Escherichia coli K99-specific monoclonal antibody. Infect Immun 1983; 42: 653-658.

15. Culbertson JT. Natural transmission of immunity against Trypanosoma lewisi from mother rats to their offspring. $J$. Parasitol 1938; 24: 62-82.

16. Bruce-Chwatt LJ, Gibson FD. Transplacental passage of Plasmodium berghei and passive transfer of immunity in rats and mice. Trans $R$ Soc Trop Med Hyg 1956; 50: 47-53. 